\title{
Prenatal diagnosis of a variant of the azygos venous system
}

\author{
Clelia Lo Verso ${ }^{1 *}$, Valentina Cigna ${ }^{2}$, Gianfranca Damiani ${ }^{2}$, Laura Lo Verso ${ }^{1}$, Rossella Conti ${ }^{3}$ and Vincenzo Duca ${ }^{3}$
}

\begin{abstract}
Background: The azygos venous system consists of the azygos vein on the right side and the hemiazygos and accessory hemiazygos on the left side. The azygos vein runs through the abdominal cavity along the right side of the vertebral bodies, in a cranial direction, passes through the diaphragm and reaches the mediastinum, where it forms the arch of the azygos which flows into the superior vena cava. Along its course, the azygos vein communicates with the intercostal veins on the right, the hemiazygos vein that collects blood from the left lower intercostal veins, and accessory hemiazygos vein that drains into the left upper intercostal veins. The last two, at the level of the seventh thoracic vertebra, unite and end in the azygos vein. The accessory hemiazygos vein is normally included in the length between T4 and T8. The embryological origin of the accessory hemiazygos vein is the result of an expansion in the direction of the cranial hemiazygos vein, which comes from the left upper sovracardinale vein (Dudiak et al. in Semin Roentgenol 24(1):47-55, 1989; Radiographics 11(2):233-246, 1991; Webb et al. in Am J Roentgenol 139(1):157-161, 1982).
\end{abstract}

Findings: This case report describes a rare variant of azygos vein system identified in prenatal diagnosis and confirmed by postnatal ultrasonography.

Conclusions: The observation of the patient has excluded hemodynamic alterations associated with vascular anomaly.

Keywords: Azygos vein, Hemiazygos vein, Accessory hemiazygos vein, Variants, Prenatal diagnosis

\section{Findings}

Our study has focused on a 27-year-old woman, in first pregnancy at a gestational age of 38 weeks, who has been submitted to fetal echocardiography. During the investigation it has been identified the presence of a vessel with parallel course, rear and left to thoracic aorta (Fig. 2). The prenatal ultrasonography with color Doppler has showed a hemiazygos accessory vein that, from the diaphragmatic dome, joining with the superior intercostal vein, seemed to drain into the venous trunk brachial-cephalic left (Fig. 3). We have assumed it was a rare variant of the azygos vein system: the hemiazygos and accessory hemiazygos veins form common channels which drain into the brachiocephalic vein (Fig. 1) (Blackmon and Franco

\footnotetext{
*Correspondence: clelia.l@alice.it

${ }^{1}$ Department of Sciences for Health Promotion and Mother and Child Care, Palermo University, Palermo, Italy

Full list of author information is available at the end of the article
}

2011). The accessory hemiazygos vein, also called the superior hemiazygos vein, drains into the superior left hemithorax. In the majority of cases there is a small connection to the left superior intercostal vein, and rarely, $1-2 \%$ of the time, the accessory hemiazygos vein drains into the brachiocephalic vein (Galwa et al. 2007).

We have started a follow-up with prenatal echocardiography. The patient was born by caesarean section at $40+4 \mathrm{w} . \mathrm{g}$, weight $3280 \mathrm{~g}$, stature $50 \mathrm{~cm}, \mathrm{CC} 34 \mathrm{~cm}$, Apgar $1^{\prime}: 9,5^{\prime}: 10$. He has had a good adaptation to extrauterine life. Postnatal echocardiography has confirmed the presence of a hemiazygos accessory vein that drains into the left brachial-cephalic trunk (Fig. 4). The ultrasound examination has showed no other anatomical or functional cardiac abnormalities. Through color-Doppler it has been possible to confirm the absence of hemodynamic changes in accordance with following the vascular variant. 


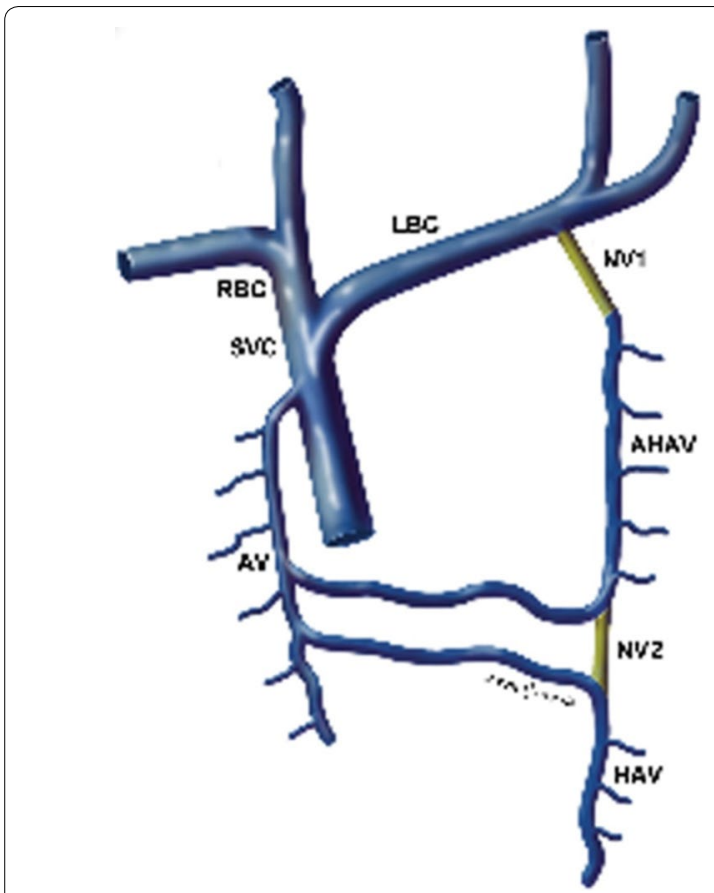

Fig. 1 Reconstruction of the anatomical variant of azygos vein system identified in this patient: the hemiazygos and accessory hemiazygos veins form common channels which drain into the brachiocephalic vein

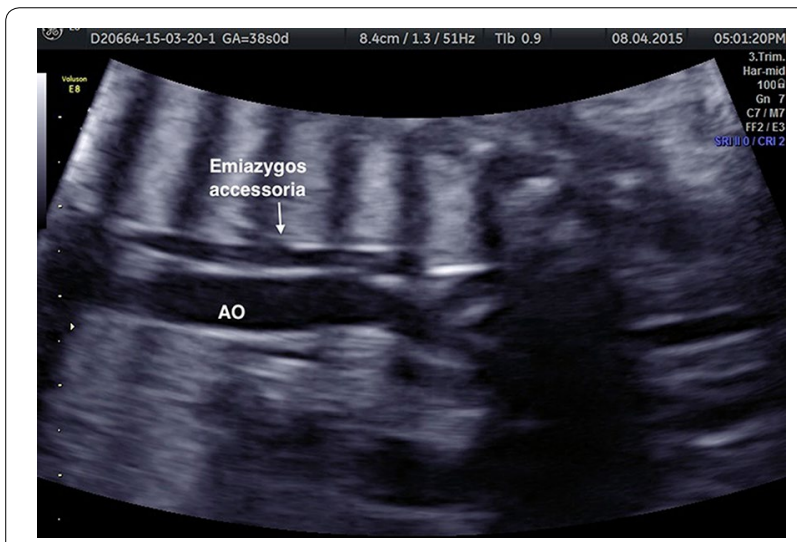

Fig. 2 The prenatal ultrasound shows a vessel with parallel course on the left and posteriorly to the thoracic aorta

\section{Conclusions}

This vascular anomaly has never been detected prenatally. The clinical case we have described is the ideal diagnostic procedure to be followed in a patient with vascular malformation. The prenatal recognition of the vascular anatomy has allowed us to monitor the patient since fetal life and to orient the mode of delivery and assistance at birth. The prenatal ultrasound follow-up has been crucial to monitor the heart function of the

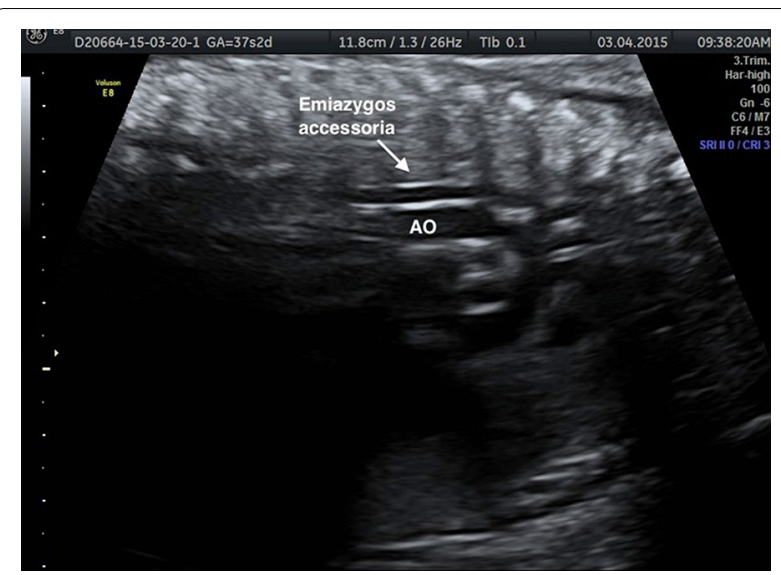

Fig. 3 The prenatal ultrasound shows the accessory hemiazygos that drain into the left venous trunk brachial-cephalic

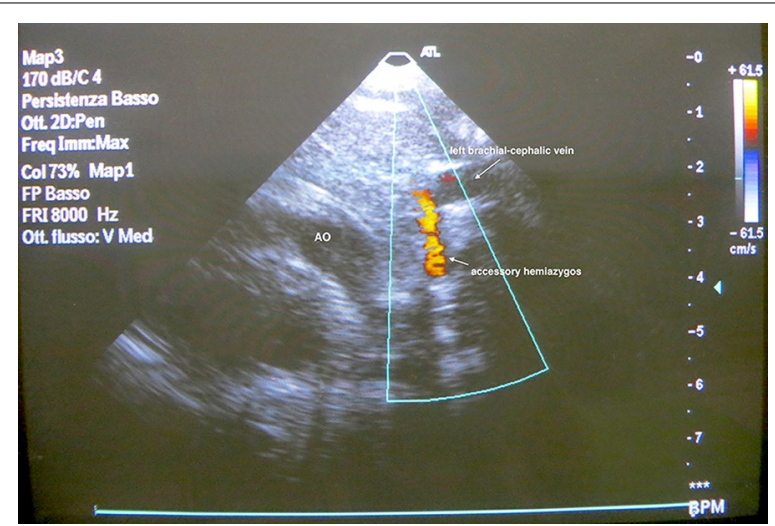

Fig. 4 The postnatal echocardiography, through color-Doppler, shows the anterograde flow of blood draining in the left brachiocephalic trunk, as reconstructed in anatomical model in Fig. 1

fetus, as it has excluded conditions of volume overload and pressure overload of the heart chambers, and to see any other cardiac malformations. We have excluded that this variant of the azygos venous system represents an indication to early cesarean section. Finally, the postnatal ultrasound follow-up has confirmed that this anomaly does not cause hemodynamic vascular changes and does not expose the patient to other cardiovascular complications.

In the management of this case report, it has been very important the collaboration between gynecologists and neonatologists who have accompanied the mother and her unborn child with prudence and expertise providing them with the best care.

\section{Abbreviations}

IVC: inferior vena cava; w.g.: weeks of gestation; CC: head circumference. 


\section{Authors' contributions}

All authors have personally participated in the research and/or article preparation and have read and approved the final article before submission. VD has promoted the conception and design of the study and has made a major contribution to all steps of manuscript production. CLV, VC and LLV have participated in acquisition, analysis and interpretation of data and to the first draft of the manuscript. GD and RC have contributed to acquisition and interpretation of data and critical revision of the manuscript. All authors read and approved the final manuscript.

\section{Author details}

${ }^{1}$ Department of Sciences for Health Promotion and Mother and Child Care, Palermo University, Palermo, Italy. ${ }^{2}$ U.O.S. Fetal Medicine and Prenatal Diagnosis, A.O. Hospital Villa Sofia-Cervello, Palermo, Italy. ${ }^{3}$ U.O. of Neonatology and NICU, A.O. Hospital Villa Sofia-Cervello, Palermo, Italy.

\section{Competing interests}

The authors declare that they have no competing interests.

\section{Informed consent}

The patient has given her consent for the inclusion of her personal and medical data in the manuscript. No sponsors supported the paper for publication.
Received: 12 November 2015 Accepted: 29 July 2016

Published online: 11 August 2016

\section{References}

Blackmon JM, Franco A (2011) Normal variants of the accessory hemiazygos vein. Br J Radiol 84(1003):659-660

Dudiak CM, Olson MC, Posniak HV (1989) Abnormalities of the azygos system: CT evaluation. Semin Roentgenol 24(1):47-55

Dudiak CM, Olson MC, Posniak HV (1991) CT evaluation of congenital and acquired abnormalities of the azygos system. Radiographics 11(2):233-246

Galwa RM, Prakash M, Khandelwal N (2007) 16-MDCT depiction of the accessory hemiazygos vein draining into the left brachiocephalic vein. Indian J Radiol Imaging 17:50-51

Webb WR, Gamsu G, Speckman JM, Kaiser JA, Federle MP, Lipton MJ (1982) Computed tomographic demonstration of mediastinal venous anomalies. Am J Roentgenol 139(1):157-161

\section{Submit your manuscript to a SpringerOpen ${ }^{\circ}$ journal and benefit from:}

- Convenient online submission

- Rigorous peer review

- Immediate publication on acceptance

- Open access: articles freely available online

- High visibility within the field

- Retaining the copyright to your article

Submit your next manuscript at springeropen.com 